\title{
ESTETIKA GASTRONOMI NUSANTARA DALAM MEDIA DIGITAL
}

I.I. PRATIWI

Received: 18 April 2021; Accepted: 31 Mei 2021; Published: 30 Juni 2021

Ed. 2021; 4 (2): 248 - 257

\begin{abstract}
The development of the digital world affects how humans perceive aesthetics in digital media. Including how the Indonesia gastronomic presentation is perceived in digital media both visually and audio. Gastronomy is the study of food and food culture. The development of digital information technology creates a space that is full of information, how can information about the Indonesian gastronomy continue to exist in the midst of cross-cultural information on today's digital media. People's behavior is influenced by the perceptions of netizens formed from digital information media, be it social media, television media, film media, even entertainment media on demand. This study uses a phenological approach to describe how the Indonesian gastronomic aesthetics are presented in various digital media platforms, namely social media Instagram, social media Facebook, social media Youtube, digital television media, digital film media, and entertainment digital media on demand. The data was obtained through observation of these various digital media platforms. This study produces a comparison of the aesthetic elements used in each of these digital media and how the existence of Indonesian gastronomy is presented in it.
\end{abstract}

Keywords: Digital Media, Indonesian Gastronomy, Gastronomy Aesthetic, Food Aesthetic, Culinary Aesthetic.

\section{PENDAHULUAN}

Dalam kurun waktu 10 tahun terakhir ini perkembangan media digital dipengaruhi oleh diperkuatnya jaringan teknologi informasi. Di Indonesia saja, program pemerataan jaringan komunikasi masih terus menjadi program prioritas pemerintah.

Kondisi pandemic Covid-19 yang membatasi pergerakan dan interaksi manusia semakin mendorong kebijakan pemerintah dalam pengembangan dan pemerataan teknologi serta media komunikasi. Tidak beroperasinya mall, bioskop, ruang-ruang publik, sekolah dan kampus, serta kebijakan pembiasaan masyarakat yang diam di rumah selama pandemic Covid-19 memberikan ruang bagi media digital untuk semakin meresap dalam keseharian masyarakat. Media komunikasi digital dianggap sebagai solusi untuk pembatasan pergerakan dan interaksi antara masyarakat, dimana hampir seluruh kegiatan utama masyarkat diselenggarakan menggunakan teknologi komunikasi digital ini. Belanja memenuhi kebutuhan sehari-hari, menggunakan aplikasi digital. Bersekolah menggunakan aplikasi Google Classroom dan google meet. Bekerja menggunakan 
aplikasi zoom meeting dan whatsapp. Mencari informasi menggunakan aplikasi Google Search. Bersosialisasi dan bersilaturahmi menggunakan aplikasi sosial media. Sampai beribadah pun menggunakan aplikasi zoom conference.

Ketergantungan manusia pada aplikasiaplikasi yang berkembang dalam media digital memengaruhi pola hidup masyarakat zaman sekarang yang memiliki dua ruang kehidupan, yaitu ruang kehidupan nyata dan ruang kehidupan digital. Hal ini merubah pola perilaku masyarakat dalam mencerna informasi dan memanfaatkan waktu untuk mengerjakan beberapa hal sekaligus secara pararel. Sambil menjaga anak bermain misalnya, sang ibu bisa menggunakan waktu untuk berbelanja dengan melihat-lihat antar toko di Tokopedia atau Shopee misalnya, memasukkan ke daftar keinginan (wishlist), dan melakukan transaksi di lain waktu. Para pelajar misalnya, bisa melakukan masuk ke dalam perkuliahan kampus tetapi sembari mengikuti webinar di belahan dunia yang lain. Sifat pararel dari pola bekerja secara digital ini akan melahirkan generasi yang mampu menyelenggarakan pekerjaan secara multitasking dan akan kesulitan jika harus mengikuti pola bekerja yang sesuai dengan aturan lama.

Media digital merupakan media yang penuh dengan informasi lintas geografis dan lintas budaya. Media digital dirancang pula dengan algoritma pemrograman yang membuat kelompok informasi yang menjadi minat dari seseorang akan muncul berdasarkan historis pencarian di masa lampaunya. Bila seseorang menyukai tentang tanaman misalnya, dalam media social yang digunakannya, informasi berkaitan dengan tanaman akan muncul berulang kali. Hal ini berdampak pada informasi-informasi yang kurang popular akan semakin tenggelam. Termasuk juga informasiinformasi yang berkaitan dengan kebudayaan yang mungkin kurang popular tetapi memiliki skala kepentingan yang cukup tinggi, tidak akan sampai pada target audiensnya melalui algoritma yang saat ini berkembang di masyarakat. Atas dasar pemikiran itulah, maka dirasa penting untuk menelaah bagaimana budaya nusantara dicitrakan dalam media digital, termasuk budaya gastronomi nusantara.

Gastronomi merupakan ilmu tentang makanan dan budaya makanan. Menurut TURGARINI (2018) terdapat 9 (sembilan) aspek penting dalam gastronomi, dapat dilihat dalam Fig 1 berikut ini.

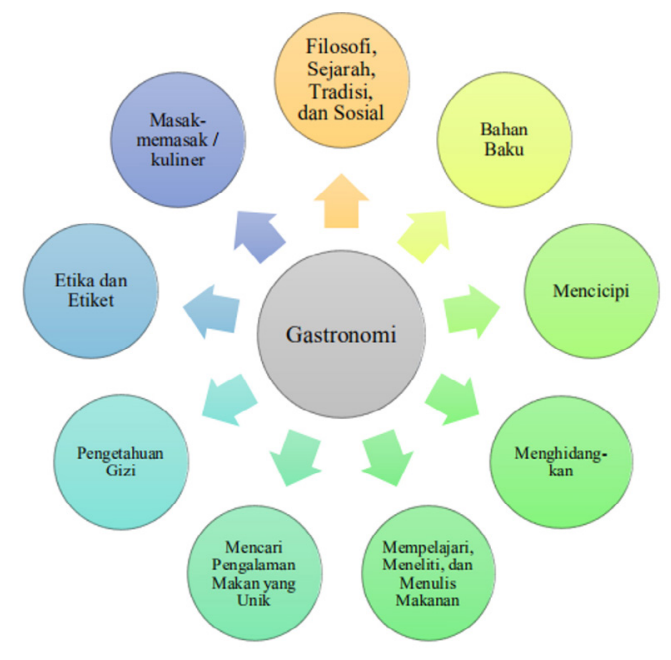

Gambar 1. Komponen Gastronomi. Sumber : Turgarini (2012)

Gastronomi akan berkaitan dengan filosofi, sejarah, tradisi, social, etika dan etiket yang berhubungan dengan makanan. Gastronomi juga berkaitan dengan bahan baku dan pengetahuan gizi makanan. Gastronomi berkaitan juga dengan kegiatan mencicipi, memasak, serta menghidangkan makanan. Gastronomi akan berhubungan juga dengan mempelajari, meneliti dan menulis tentang makanan. Gastronomi berhubungan juga dengan pengalaman makan yang unik dalam hal ini melakukan wisata (TURGARINI, 2018). 
Gastronomi nusantara merupakan komponen-komponen gastronomi yang mengulas mengenai kekayaan budaya gastronomi yang dimiliki oleh Indonesia yang memiliki latar budaya yang berbeda-beda. Gastronomi nusantara bisa merupakan gastronomi tradisional yang lahir dari adat istiadat yang berhubungan dengan makanan dari sisi bahan baku makanan tradisional, jenis makanan tradisional, cara memasak makanan tradisional, sampai cara menghidangkan makanan tradisional. Gastrononomi nusantara dapat pula menggambarkan inovasi makanan nusantara dalam bentuk makanan fushion, makanan kreasimasa kini bahkan makanan yang memanfaatkan teknologi pengolahan pangan yang merupakan hasil dari kreatifitas dan penciptaan makanan sebagai salah satu objek karya seni, misalnya gastronomi molekuler nusantara. Gastronomi nusantara merupakan makanan lokal yang dapat digunakan sebagai alat untuk membedakan satu budaya dengan budaya lainnya yang dapat memberikan identitas budaya (DU RAND GE, 2003). Gastronomi nusantara lahir dari adanya kekayaan budaya Indonesia yang tersebar pada 17.508 pulau yang ada di Indonesia, yang memiliki factor geografis, iklim dan historis yang berbeda yang berpengaruh pada budaya makanannya. Sejarah perdagangan rempah di masa lampau, eksistensi kerajaan nusantara serta penjajahan yang terjadi di Indonesia turut memberikan kekayaan budaya gastronomi nusantara Indonesia yang sampai masa kini masih bisa dilihat pengaruhnya pada budaya gastronomi Indonesia (WIJAYA, 2019).

Estetika gastronomi nusantara diartikan sebagai bagaimana gastronomi nusantara dicitrakan dengan memenuhi komponenkomponen estetis. Baik dari sisi kreator maupun penikmat media digital. Dimana bisa dipahami bahwa estetika yang berfokus pada creator akan menerjemahkan keindahan seni atau estetis dalam kaitannya dengan penciptaan produk makanan sebagai objek estetis dengan maksud penciptaan tersebut menghasilkan respon estetis dalam media digital (EATON, 2010). Sementara dari sisi penikmat rangsangan estetika gastronomi nusantara tersebut mampu menciptakan pengalaman estetis yang dapat memunculkan beberapa tingkatan respon, misalnya secara psikologis maupun secara sikap. Secara psikologis misalnya, jadi timbul selera makan, ingin mencoba makanan, atau ingin mencoba membuat makanan. Sementara secara sikap misalnya melakukan perilaku membeli makanan, memakan makanan, memasak makanan maupun merekomendasikan makanan.

Dalam media digital, akan melibatkan perangsangan inderawi visual yang melibatkan indera pelihat dan audio yang melibatkan indera pendengaran. Sementara rangsangan inderawi yang tidak diperoleh adalah rangsangan indera penciuman dalam bentuk bau dan aroma, serta rangsangan indera peraba dalam bentuk sentuhan, dan rangsangan indera pengecap dalam bentuk rasa. Hilangnya tiga sensor inderawi dalam estetika gastronomi nusantara yang disajikan dalam media digital, seringkali harus menjadikan dua rangsangan inderawi lainnya (visual dan audio) dimunculkan dengan berlebihan. Sebagai contoh, dengan penyajian foto makanan yang bisa ditemukan di Gofood maupun di Instagram. Maka penataan foto makanan tersebut harus mampu merangsang pengalaman estetis penikmat agar mampu menimbulkan respon terhadap rangsangan visual tersebut, misalnya dengan melakukan pemesanan makanan Kreator dibelakan layar yang menciptakan karya visual berkaitan dengan makanan bukan main-main, profesi yang muncul diantaranya adalah fotografer makanan, pengarah gaya makanan (food 
stylist), chef serta pengelola blog makanan (BENDERSKY, 2014).

Perkembangan terkini berkaitan dengan gastronomi dalam media digital berkembang karena perkembangan media social Youtube, Instagram dan Tiktok. Berbagai platform tersebut digunakan oleh para pengelola akun media social yang mengembangkan kanalkanal yang berhubungan dengan review makanan sampai mukbang (makan besar). Mukbang merupakan gaya makan besar yang muncul dari vlogger-vlogger Korea. Berbeda dengan sebagian besar budaya di Indonesia yang menggambarkan makan sebagai bagian dari etika dan sopan santun dengan makan dengan aturan. Dalam budaya Asia Timur, makan dengan mengecap atau mengeluarkan suara merupakan bagian dari budaya yang menggambarkan kenikmatan makan, penghargaan terhadap yang memasak dan menyajikan makanan, serta menimbulkan suasana kebahagiaan. Sehingga beberapa kanal mukbang menjadi populer dan menjadi bagian daripada estetika gastronomi yang berkembang dari creator Asia Timur. Selain rangsangan visual, rangsangan audio disini menjadi penting dengan menggunakan microphone yang memiliki sensitifitas perekaman bunyi yang cukup baik, sehingga mampu merekam suara-suara detail saat menyantap makanan.

Studi ini bertujuan untuk merekam beberapa fenomena gastronomi nusantara yang berhasil disajikan secara estetis dalam media digital masa kini. Teknik observasi dan studi literature digital dilakukan dalam mengumpulkan data, sementara data diolah secara analisis kualitatif deskriptif. Pembatasan dilakukan pada kanal-kanal media digital berupa sosial media Youtube, Instagram, Facebook, Film, Acara Televisi, serta Media Entertainment on Demand seperti Netflix dan Viu. Bagaimana estetika gastronomi nusantara dipresentasikan dalam kanal-kanal media digital tersebut dan seberapa besar porsinya dalam media digital tersebut merupakan inti dari penyelenggaraan studi ini.

\section{PEMBAHASAN}

Media digital yang mengangkat gastronomi secara umum berkembang diawali dengan adanya perkembangan blog sejak tahun 2002 dan website yang dikelola pribadi. Pandangan para blogger makanan untuk hidangan tertentu atau masakan telah memanfaatkan peluang pemasaran yang besar. Ulasan dalam blog dapat menarik orang lebih dan lebih ke tempat yang menyajikan jenis makanan atau masakan yang sama (PHILIP, 2016). Jika melakukan pencarian melalui google search engine dengan kata kunci - kata kunci tertentu, maka muncul beberapa hasil yang dapat dilihat dalam tabel 1 berikut ini.

Table 1. Pencarian Google Blog Gastronomi Nusantara.

\begin{tabular}{|l|l|l|l|}
\hline No & Kata Kunci & Hasil & Waktu \\
\hline 1 & Blog Kuliner & 47.000 .000 & 0,48 \\
\hline 2 & Blog Gastronomi & 3.230 .000 & 0.49 \\
\hline 3 & $\begin{array}{l}\text { Blog Kuliner } \\
\text { Indonesia }\end{array}$ & 27.100 .000 & 0.53 \\
\hline 4 & $\begin{array}{l}\text { Blog Gastronomi } \\
\text { Indonesia }\end{array}$ & 68.000 & 0.48 \\
\hline 5 & $\begin{array}{l}\text { Blog Kuliner } \\
\text { Nusantara }\end{array}$ & 1.810 .000 & 0.55 \\
\hline 6 & $\begin{array}{l}\text { Blog Gastronomi } \\
\text { Nusantara }\end{array}$ & 21.900 & 0.47 \\
\hline
\end{tabular}

Salah satu blog yang cukup baik merepresentasikan gastronomi nusantara diantaranya adalah pettyelliott.com yang dikelola oleh orang Indonesia yang lama tinggal di Inggris dan membuka kelas memasak di Inggris. Pada tahun 2002 sepulang ke Indonesia, Petty semakin giat menulis tentang makanan Indonesia hingga terbit buku memasaknya Papaya Flower di tahun 2014. Blog yang dikelola oleh Petty Elliot membagikan 
informasi berkaitan dengan resep masakan Indonesia, foto-foto makanan fushion Indonesia, foto-foto bahan baku makanan Indonesia, dan belakangan dalam blog yang dikelola beliau juga menjual produk bumbu makanan dengan merek Rasaku selain buku masak yang dijualnya yaitu Papaya Flower dan Jakarta Bites. Blog Petty Elliot ini hanya salah satu dari bagaimana presentasi estetik dari gastronomi nusantara dalam media digital yang cukup baik dilakukan dan diakses pula oleh masyarakat mancanegara karena blog yang dikelola berbahasa Inggris.

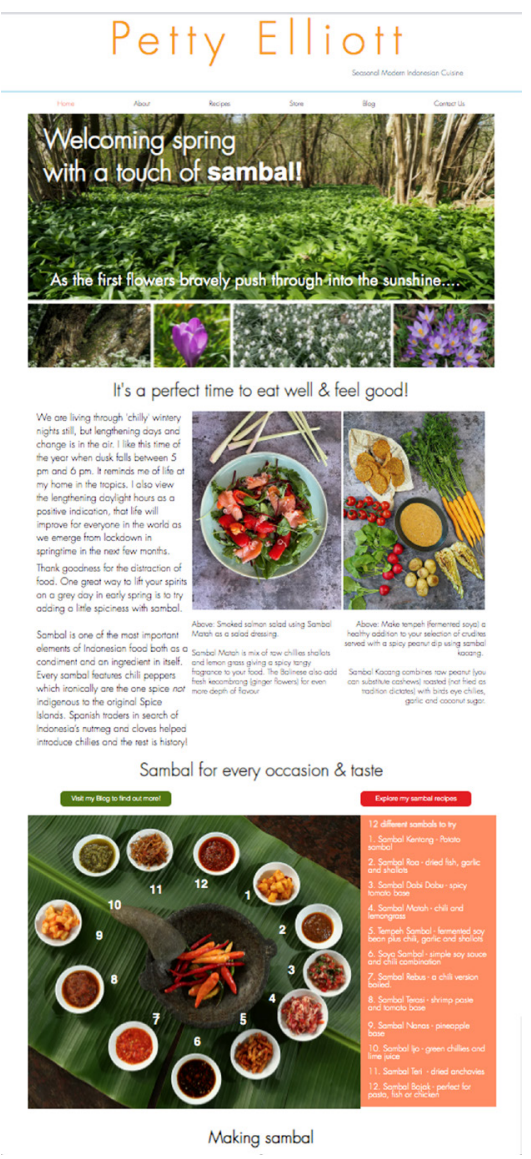

Gambar 2. Blog MIlik Petty Eliot.

Sumber: htt ps://www.pettyelliott.com/
Dalam media social Instagram, presentasi makanan cukup beragam diantaranya merupakan review makanan, photo makanan sampai resep makanan. Instagram merupakan media social yang digunakan pula sebagai etalase social baik produk maupun persona. Sebagaimana observasi yang dilakukan dalam Forbes India pada tahun 2017, perilaku memotret dan membagikan potret makanan sudah menjadi kebiasaan baru dengan adanya perkembangan gawai pintar dan media social (BANARJEE, 2017). Photo makanan yang dibagikan dalam social media dianggap sebagai perpanjangan budaya dan gaya hidup masa kini (LEWIS, 2020). Ada istilah yang digunakan sebagai pengelola akun social media pribadi yang banyak mengulas mengenai kuliner nusantara, yaitu adalah foodie atau travel foodies. Menurut phinemo.com, ada 22 foodies yang perlu difollow akunnya karena memberikan informasi rekomendasi kuliner kekinian bahkan otentik dan legendaris Indonesia. Beberapa akun diantaranya adalah:@riasukmawijaya, @ mgdalenaf,@nexcarlos,@myfunfoodairy,@ jajanbakso,@henjiwong,@tanboy_kun,@ kenandgrat,@gerrygirianza,@anakjajan,@ inijie,@eatandtreats,@dj_kattybutterfly36, @JWestBros, @kokobuncit, @filipusverdi, @kulineran_yk, @kokokulineran, @ fooddirectory,@dyodoran,@anitajoyo dan @foodventurer (SULISTIARMI, 2020). Mayoritas daripada foodie tersebut mengelola pula akun Youtube sementara Instagram kembali digunakan sebagai kanal etalase, karena Instagram tidak memberikan monetasi terhadap tayangannya. Sementara Youtube dianggap sebagai kanal yang memberikan ruang bagi konten creator untuk memperoleh uang dari konten yang diunggahnya. 

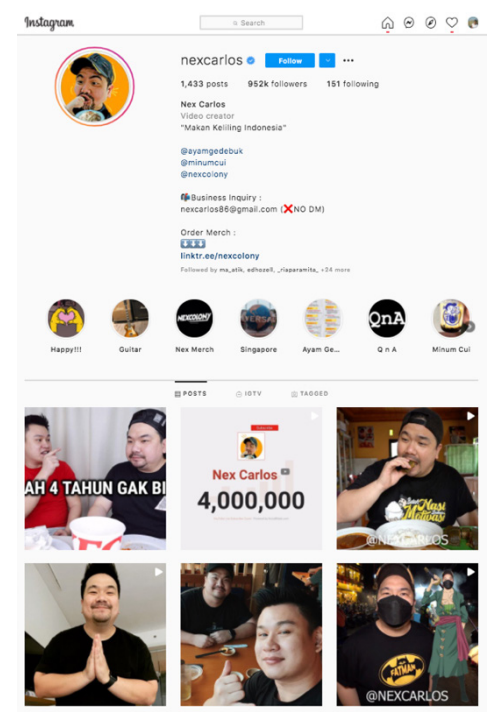

Gambar 3. Instagram Nex Carlos

Sumber: https://www.instagram.com/nexcarlos

Jika melihat akun Youtube, dan melakukan pencarian dengan beberapa kata kunci seperti dalam teknik pencarian google search.

Maka ditemukan hasil pencarian seperti dalam tabel 1. Maka beberapa nama foodies Instagram muncul sebagai pencarian utama (top search). Nama MGDALENAF, Tanboy Kun, Nex Carlos, Makanmana, MYFUNFOODDIARY, serta beberapa tayangan televisi yang diunggah ke Youtube seperti channel Trans7 Official, Trans TV Official, dan Netmediatama. Penarik utama dari postingan dalam Youtube adalah gambar sampul video dan judul video yang dibuat semenarik mungkin. Sementara konten populer dari gastronomi nusantara yang diangkat adalah berkaitan dengan review makanan.

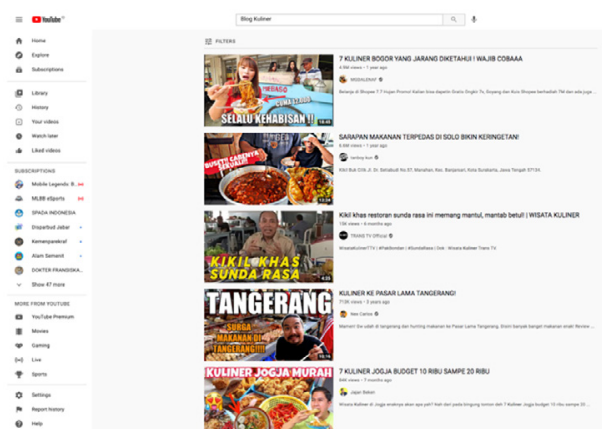

Gambar 4. Tangkapan Layar Youtube.com Sumber: diolah peneliti
Sementara, untuk media social Facebook dengan menggunakan kata kunci kuliner Indonesia maka berbagai Facebook grup muncul, dan uniknya Facebook memiliki grupgrup yang banyak dikelola untuk bisnis kuliner Indonesia, hal ini yang menjadi pembeda dari platform media digital lainnya yang kebanyakan melakukan review masakan. Dalam platform Facebook, review dan membagikan resep makanan tetap ada tetapi hanya di Facebook terdapat fasilitas grup yang memungkinkan penggunanya membagikan informasi khusus terkait suatu produk yang dibuatkan grup khususnya. Sehingga memungkinkan interaksi langsung antar anggota grup tanpa melibatkan orang-orang non anggota grup. Jika melihat pola komunal, maka Facebook lebih cocok jika disebut sebagai media social, karena level interaksi yang lebih memungkinkan antar penggunanya.

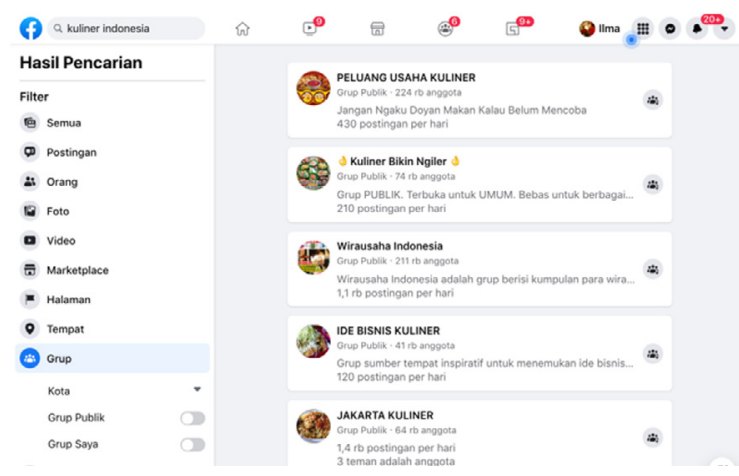

Gambar 5. Tangkapan Layar Facebook.com Sumber: diolah peneliti

Munculnya kebutuhan tayangan-tayangan televisi digital di bidang makanan juga memberikan warna tersendiri berkaitan dengan estetika gastronomi nusantara. Beberapa jenis tayangan diantara adalah acara memasak, acara wisata kuliner serta acara kompetisi memasak. Literasi gastronomi yang dimunculkan di masing-masing konsep acara berbeda-beda. Misalnya untuk acara wisata kuliner dimunculkan review dan pengalaman berwisata kuliner, 
sementara untuk acara kompetisi memasak, gastronomi dimunculkan sebagai bentuk dari pencapaian keahlian memasak, mengolah dan menyajikan makanan. Secara visual, teknik editing berpengaruh dalam proses mencerna estetika gastronomi yang dimunculkan. Misal ketegangan dari pemotongan gambar dan pengaruh sound effect dalam acara kompetisi memasak memberikan pengalaman estetis tersendiri. Tantangan yang diberikan dalam kompetisi memasak tersebut seringkali mengangkat kepopuleran makanan tradisional Indonesia. Salah satu kompetisi memasak yang cukup terkenal adalah Master Chef Indonesia, dimana acara kompetisi MasterChef ini merupakan salah satu waralaba acara televisi yang diadopsi dalam tayangan di Indonesia.

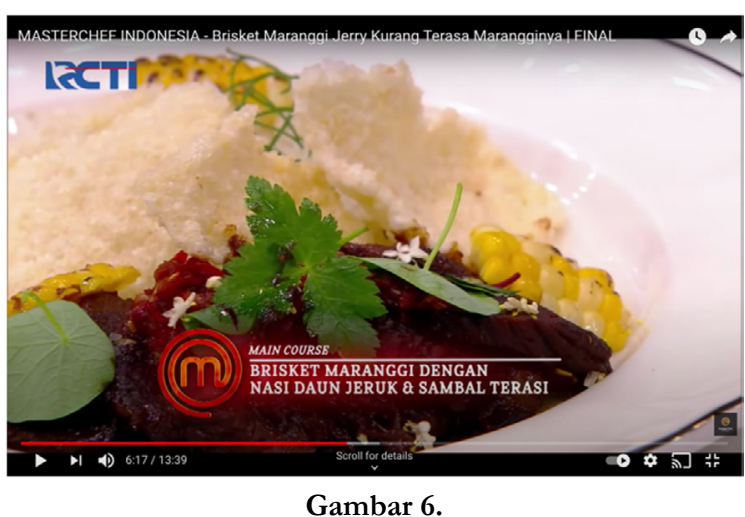

Tangkapan Layar Program Masterchef Indonesia Sumber: Youtube Master Chef Indonesia

Sementara, berkembangnya literasi gastronomi nusantara juga membuat para kreator seniman perfilman dalam mengabadikan kekayaan gastronomi nusantara dalam bentuk film. Beberapa judul yang mengangkat tema berkaitan dengan gastronomi nusantara diantaranya adalah Tabula Rasa, sebuah film yang banyak mengangkat tentang kuliner khas Minangkabau, Filosofi Kopi, sebuah film yang banyak mengangkat tentang budaya kopi di Indonesia, Aruna dan Lidahnya sebuah film yang banyak memotret makanan legendaris yang ada di Indonesia dalam gaya bercerita wisata kuliner. Dari semua judul tersebut, Filosofi Kopi dinilai sebagai salah satu film yang memiliki kesuksesan yang cukup besar dalam mengangkat budaya kopi nusantara yang mendorong pada lahirnya kebiasaan dan usaha kedai-kedai kopi di kalangan milenial.

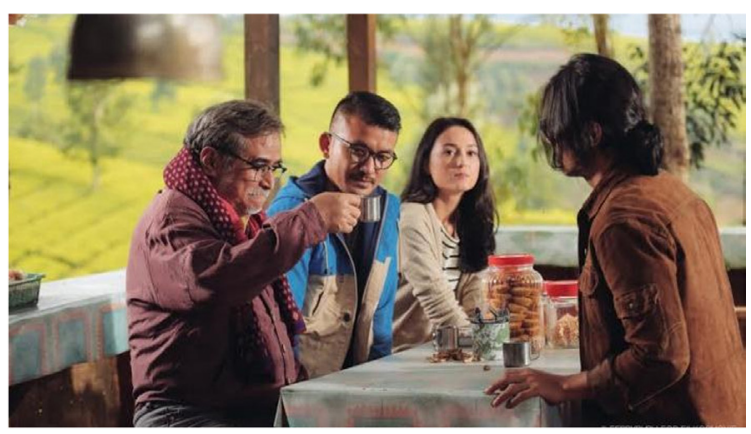

Gambar 7. Cuplikan Adegan Film Filosofi Kopi

Sumber: https://jonathanend.files.wordpress.com/2015/04/ filkop5.jpg

Lahirnya media entertainment on demand seperti Netflix, Viu, Disney Hotstar, Iflix, dan Indihome memberikan ruang bagi para konten kreator untuk berkarya dalam media baru selain film dan televisi. Beberapa program dikembangkan dalam bentuk drama series fiksi dan documenter. Platform ini sudah lebih dulu digunakan bagi kreator mancanegara, sayangnya creator Indonesia belum banyak menggunakan media ini sebagai salah satu sarana media digital yang dapat menjadi ruang ekspresi dan berkarya. Kurangnya konten yang diproduksi oleh orang Indonesia menjadikan minimnya literasi gastronomi nusantara digital ditemukan dalam media tersebut. Ada salah satu program yang dikelola oleh channel National Geography berjudul Gordon Ramsay: Uncharted yang mengangkat gastronomi nusantara dalam salah satu tayangannya yang menampilkan Chef terkenal Gordon Ramsay yang berpetualang di Sumatera Barat untuk memasak kuliner rendang bersama dengan Chef Wiliam Wongso. 


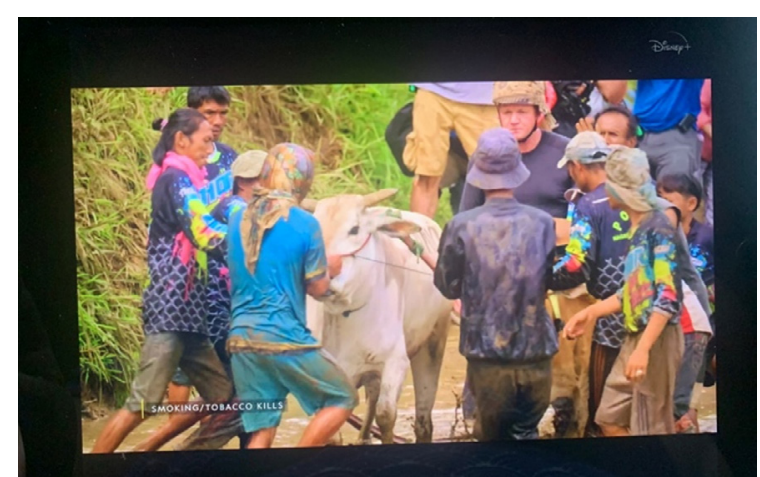

Gambar 8. Tangkapan Layar Program

Gordon Ramsay: Uncharted

Sumber: Disney+ Hotstar Channel

Beberapa perkembangan media digital dan kebutuhan masyarakat berkaitan dengan aplikasi-aplikasi digital yang dapat didownload di gawai pintar membantu memberikan solusi bagi manusia digital. Beberapa aplikasi digital yang mengangkat tentang gastronomi nusantara diantaranya dapat dilihat dalam tabel 2 berikut. Konten gastronomi digital disajikan secara visual dalam bentuk informasi berkaitan dengan gastronomi nusantara, restoran yang menyajikan, transaksi dan reservasi makanan, serta promosi diskon makanan. Beberapa aplikasi berkaitan dengan pengetahuan berkaitan dengan makanan sehat dan kegiatan menanam bahan makanan juga mulai bermunculan belakangan ini.

Table 2 Aplikasi Digital Gastronomi Nusantara.

\begin{tabular}{|l|l|l|l|}
\hline No & \multicolumn{1}{|c|}{$\begin{array}{c}\text { Nama } \\
\text { Aplikasi }\end{array}$} & \multicolumn{1}{|c|}{ Konten } & $\begin{array}{l}\text { Operating } \\
\text { Sistem }\end{array}$ \\
\hline 1 & $\begin{array}{l}\text { GoFood } \\
\text { dalam Gojek }\end{array}$ & $\begin{array}{l}\text { Pemesanan } \\
\text { Makanan }\end{array}$ & $\begin{array}{l}\text { Android } \\
\text { \& IoS }\end{array}$ \\
\hline 2 & Zomato & $\begin{array}{l}\text { Review } \\
\text { Restoran }\end{array}$ & $\begin{array}{l}\text { Android } \\
\text { \& IoS }\end{array}$ \\
\hline 3 & Traveloka & $\begin{array}{l}\text { Review } \\
\text { Restoran, } \\
\text { Promo Restoran }\end{array}$ & $\begin{array}{l}\text { Android } \\
\text { \& IoS }\end{array}$ \\
\hline 4 & Pinterest & Resep Makanan & $\begin{array}{l}\text { Android } \\
\text { \& IoS }\end{array}$ \\
\hline 5 & Cookpad & Resep-resep & $\begin{array}{l}\text { Android } \\
\text { \& IoS }\end{array}$ \\
\hline 6 & PergiKuliner & $\begin{array}{l}\text { Review } \\
\text { Restoran }\end{array}$ & $\begin{array}{l}\text { Android } \\
\text { \& IoS }\end{array}$ \\
\hline
\end{tabular}

\begin{tabular}{|l|l|l|l|}
\hline 7 & Eatigo & $\begin{array}{l}\text { Review dan } \\
\text { reservasi } \\
\text { restoran }\end{array}$ & $\begin{array}{l}\text { Android } \\
\text { \& IoS }\end{array}$ \\
\hline 8 & Hangry & $\begin{array}{l}\text { Pemesanan } \\
\text { Makanan }\end{array}$ & $\begin{array}{l}\text { Android } \\
\text { \& IoS }\end{array}$ \\
\hline 9 & Foodia & $\begin{array}{l}\text { Belanja Bahan } \\
\text { Baku Makanan }\end{array}$ & $\begin{array}{l}\text { Android } \\
\text { \& IoS }\end{array}$ \\
\hline 10 & Meser Mang & $\begin{array}{l}\text { Belanja Bahan } \\
\text { Baku Makanan }\end{array}$ & Android \\
\hline
\end{tabular}

Sumber: Diolah peneliti

Perkembangan media digital juga mencitrakan gastronomi nusantara dalam media permainan digital. Beberapa judul permainan digital yang mengangkat kuliner nusantara diantaranya adalah Gim Tahu Bulat, Gim WarungChain: Go Food Express, dan Gim Kuliner Selera Nusantara.

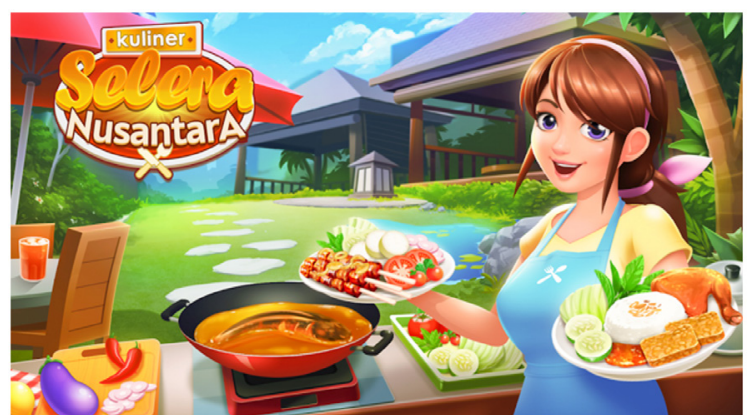

Gambar 9. Gim Kuliner Selera Nusantara Sumber: Google Playstore

\section{PENUTUP}

Bicara tentang estetika akan sangat berkaitan dengan bagaimana creator dan penikmat objek yang dinilai estetis. Bentuk dan komponen estetika akan sangat bervariasi bergantung pada pola piker masyarakat di suatu zaman. Perkembangan media digital akan merubah bagaimana sensor inderawi bekerja merespon rangsangan-rangasangan yang ada. Presentasi gastronomi nusantara dalam media-media digital tersebut akan sangat bervariasi tingkat estetisnya tergantung siapa yang mengonsumsi rangsangan estetis tersebut. Apa tujuan dari creator dalam membuat suatu objek estetis, apakah untuk sekedar meningkatkan 
kesadaran atau sampai menimbulkan suatu dorongan perilaku tertentu. Selain nilai estetis dari gastronomi nusantara dalam media digital, konten literasi yang berkaitan dengan pengetahuan gastronomi nusantara dalam media digital meruapakan salah satu hal yang juga penting untuk dilakukan dalam upaya melestarikan budaya nusantara khususnya di bidang gastronomi. Gencaran informasi dalam media digital harus menjadi kesadaran akan pentingnya menyiapkan konten-konten digital yang dapat memberikan pengetahuan dan pembekalan bagi generasi digital di masa kini dan masa yang akan datang. Karena kalau bukan creator masa kini yang menyajikan konten berkaitan dengan pelestarian gastronomi nusantara dalam media digital, pengetahuan ini akan semakin tergerus oleh pengetahuan asing yang tidak berkaitan dengan identitas bangsa Indonesia. Hal ini dikhawatirkan akan membuat bangsa Indonesia semakin kehilangan identitasnya di masa yang akan datang.

\section{KESIMPULAN}

Artikel Estetika Gastronomi Nusantara Dalam Media Digital ini dituliskan oleh Ilma Indriasri Pratiwi, SE, MPPar khusus untuk Jurnal Budaya Nusantara. Tahun 20202021, merupakan masa tantangan pandemic Covid-19 melanda dan memberikan disrupsi dalam berbagai bidang, termasuk pendidikan dan penelitian. Beberapa kegiatan penelitian dalam bentuk survey lapangan tidak dapat terselenggara sehingga muncul pendekatanpendekatan desk study dalam penyelenggaraan penelitian. Artikel ini merupakan salah satu diantaranya. Semoga sumbangsih ini dapat bermanfaat bagi pembacanya dan memberikan kekayaan perspektif lain dalam memaknai warisan budaya Indonesia di bidang gastronomi, khususnya yang berkaitan dengan perkembangan media digital di Indonesia.
Terima kasih saya ucapkan untuk pengelola Jurnal Budaya Nusantara dan seluruh civitas akademika departemen pariwisata Universitas Pendidikan Indonesia. Jika ada bertanyaan berkaitan dengan artikel ini, jangan sungkan untuk mengontak saya di alamat email ilma. indriasri@upi.edu.

\section{DAFTAR PUSTAKA}

BANERJEE J.

2017. Shoots, eats and leaves: The changing $f$ rames of food photography. Forbes India.

\section{BENDERSKY, ARI.}

2014 Food \& Art Styling Ideas. Beverly: Rockport Publishers.

\section{Du Rand Ge, Heath E, Alberts N.}

2003 The Role of Local and Regional Food in Destination Marketing: A South African Situation Analysis. J Travel Tour Mark. 2003; 14 (3/4): 97-112

EAton, Marcia Muelder.

2010. Persoalan-Persoalan Dasar Estetika. Terjemahan: Embon Kenyowati Ekosiwi. Jakarta: Salemba Humanika.

LEWIS, TANIA.

2020. Digital Food: From Paddock to Platform. Contemporary Food Studies: Economy, Culture and Politics. London: Bloomsbury Academic

PHILIP, LEENA.

2016. Impact of Food Blogs On The Reader. International Journal of Scientific \& Technology Research Volume 5, Issue 06, June 2016.

\section{SULISTIARMI, WiKE.}

2020. 22 Instagram Foodies Indonesia yang Patut Anda Follow. https://phinemo. 
com/22-instagram-foodies-indonesiaterkenal-yang-patut-anda-follow/ (diakses 15 Mei 2020)

TURgarini, D.

2018. Gastronomi Sunda Sebagai Daya Tarik Wisata di Kota Bandung. Universitas Gajah Mada.

WijAYA, SERLI

2019. Indonesian Food Culture Mapping: $A$ Starter Contribution to Promote

Indonesian Culinary Tourism. Journal of Ethnic Foods (2019) 6:9

\section{DAFTAR SITUS WEB}

https://www.pettyelliott.com/

https://www.instagram.com/nexcarlos

www.youtube.com

www.facebook.com

https://jonathanend.files.wordpress.

com/2015/04/filkop5.jpg 